\title{
AVALIAÇÃO DA CITOTOXICIDADE DO TEA TREE OIL E SUA AÇÃO ANTIMICROBIANA EM BACTÉRIA PROPIONIBACTERIUM ACNES
}

\author{
Caroline dos Santos Fogaça de Andrade'; Nilo Fuhr Batista'; Priscila Rodrigues \\ Lasakosvitsch"; Carlos Rocha Oliveira²; Valéria Maria de Souza Antunes ${ }^{2}$ \\ 'Graduandos do curso de Farmácia da Universidade Anhembi Morumbi, SP, Brasil. \\ ${ }^{2}$ Professor da Universidade Anhembi Morumbi.
}

Recebido em: jan. 2018; aceito ago. 2018; publicado out. 2018.

\section{Resumo}

Nos últimos anos, de uma maneira geral, as pessoas estão focadas tanto na saúde como na aparência e veem buscando alternativas naturais de tratamento para diversas doenças e problemas. Uma alternativa que começou a ser explorada é o uso do óleo essencial de Melaleuca alternifolia, uma planta nativa da Austrália com baixa citotoxicidade e diversas funções, dentre elas uma ação antifúngica, antiviral e antibacteriana contra muitas bactérias, como a Propionibacterium acnes, uma bactéria causadora de umas das principais doenças que acometem jovens e adultos que é a acne e a qual não se tem muitos estudos que comprovem essa ação. O objetivo deste trabalho foi avaliar a ação antimicrobiana do óleo essencial de Melaleuca alternifolia em Propionibacterium acnes através do método de Mueller Hinton e Pour Plate e sua atividade citotóxica em fibroblastos através do método de determinação do $\mathrm{IC}_{50}$ (método de exclusão por azul de tripan) e Ensaios de redução MTT à formazan e com isso conclui-se que o óleo essencial de Melaleuca Alternifolia tem baixa atividade citotóxica e alta atividade antimicrobiana contra a bactéria estudada.

Palavras-chaves: Pele. Óleo essencial de Melaleuca Alternifolia. Propionibacterium acnes. Citotoxicidade.

\section{Introdução}

$\mathrm{O}$ crescente desenvolvimento comercial e industrial na área dos óleos essenciais acompanha alterações globais, ocorrendo atualmente a maior produção em países exteriores à Europa tais como o Brasil (29\%), a Índia (26\%), os Estados Unidos (17\%) e a China (9\%). No entanto, o consumo e a preocupação com o controle de qualidade e com os aspectos relacionados com a saúde humana são particularmente significativos na Europa (MARTINS, et al, 2011). Devido à despreocupação de alguns países, a adulteração de óleos essenciais tem sido uma prática constante e a determinação dos índices físico-químicos de densidade, rotação ótica e índice de refração são de extrema importância para detectar adulterações, muito comuns na comercialização dos óleos essenciais (SANTOS, et al, 2009). Por isso a normalização dos óleos essenciais tem posto em evidência os seus benefícios, mesmo em mercados onde juntamente com a intensificação da procura, a adulteração e a deficiência de controle são por vezes fatores críticos (MARTINS, et al, 2011).

A Melaleuca alternifolia Cheel, conhecida comumente como Tea Tree, é uma planta da famí- 


\section{Brazilian Journal of Natural Sciences | Versão On-line ISSN 2595 - 0584 \\ Edição no 1- vol. 3 - outubro 2018 | www.bjns.com.br}

lia Myrtaceae nativa da costa subtropical nordeste australiano (SILVA, 2001). Seu óleo é obtido das folhas (SIMÕES et al, 2002) e sua cor vai de incolor a amarelo pálido (WHO, 1999). O óleo é composto principalmente por Hidrocarbonetos (Monoterpernos e Sesquiterpenos), Álcoois (Monoterpenóides e Sesquiterpenóides) e Óxidos. (SILVA, 2004).

Recentemente ganhou uma reputação como antisséptico seguro, eficaz e natural sendo atualmente incorporado como antimicrobiano principal ou como conservante natural em produtos farmacêuticos e cosméticos de uso externo (COX, et al., 2000).

Apesar de sua popularidade como agente antimicrobiano, há poucos estudos que comprovam sua eficácia na diminuição de Propionibacterium acnes, que faz parte da biota natural da pele sendo o principal microrganismo envolvido na etiopatogenia da acne vulgar, uma doença dermatológica que acomete a saúde em seu completo estado de bem-estar físico, mental e social e comumente afeta jovens e adultos em todo mundo. Para garantir seu uso tópico é necessário ter conhecimento sobre a pele, o maior órgão do corpo humano, que tem como suas principais camadas, a derme e a epiderme, que se assentam em uma terceira camada, chamada hipoderme, além disso, deve ser estudado se há atividade citotóxica do óleo contra as células desse órgão.

\section{Aspectos botânicos}

A Melaleuca alternifolia Cheel, conhecida comumente como tea tree, é uma planta da família Myrtaceae nativa da costa subtropical nordeste australiana (SILVA, 2001). O termo - tea tree, aparentemente, foi dado pelo Capitão James Cook em sua viagem exploratória pela Austrália em 1770, quando encontrou um arbusto de Myrtaceae, possivelmente uma espécie de Leptospermum sp., cujas folhas eram usadas pelos marinheiros em substituição ao chá de Camellia sinensis. (MAIDEN e BETCHE, 2013).

Essa árvore pode atingir até sete metros de altura, têm uma casca fina e folhas longas e pontiagudas que, quando partidas, emitem um aroma forte (SIMÕES, 2002). A cor do óleo dessa planta vai de incolor a amarelo pálido (WHO, 1999). A descrição olfativa de seu aroma pode ser: fresco, amadeirado, herbal, balsâmico e pungente (SILVA, 2001) e suas flores são amarelas ou púrpuras e naturalmente crescem em áreas pantanosas, porém já foram adaptadas a outros ambientes pelo homem (WALTERS, 2000). Na figura 1, estão representados arbustos de Melaleuca alternifolia, folhas e flores.

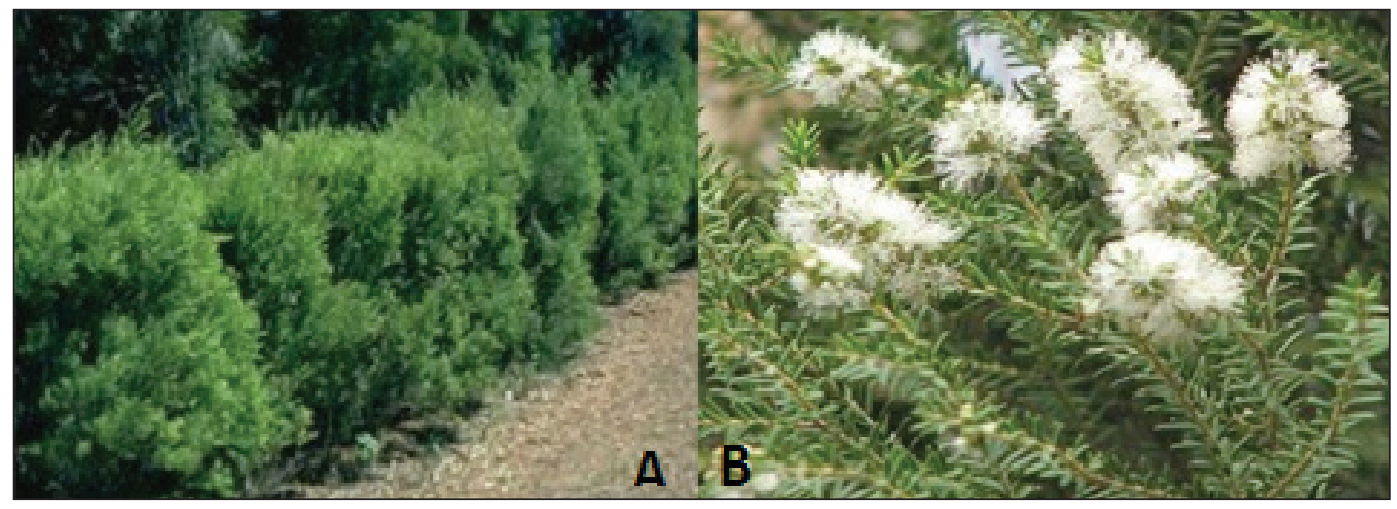

Figura 1: Fotografias de Melaleuca alternifolia. A) Planta inteira. B) Destaque para as flores Fonte: A) Melaleuca alternifolia (Cheel.), 2008a e B) Melaleuca alternifolia (Cheel.), $2008 \mathrm{~b}$.

\section{Constituintes}

O óleo, que é obtido das folhas (SIMÕES et $a l, 2002)$, é composto principalmente por Hidro- carbonetos (Monoterpernos e Sesquiterpenos); Álcoois (Monoterpenóides e Sesquiterpenóides) e Óxidos. (SILVA, 2004). Dentre esses compostos, pode conter quantidades variadas de terpe- 
nos (pineno, terpineno e cimeno), terpinenol (terpinen-4-ol), sesquiterpenos e cineol, que são os constituintes mais importantes relacionados à atividade antimicrobiana (SIMÕES et al, 2002). Além destes componentes, a melaleuca apresenta pelo menos 48 componentes orgânicos, alguns dos quais raramente foram encontrados em outras plantas (CORAZZA, 2002). A concentração de cineol depende da época em que a melaleuca é colhida; no inverno há um aumento da concentração deste composto, época ideal para colheita, pois poderia aumentar a propriedade antimicrobiana, em oposição ao verão, onde a concentração está diminuída (VADEMÉCUM, 2003). O Quadro 1 demonstra componentes da Melaleuca alternifolia.

\begin{tabular}{|c|c|c|c|}
\hline \multicolumn{2}{|c|}{ Classe } & Constituintes Principais & Composição \% \\
\hline \multirow{20}{*}{ Hidrocarbonetos } & \multirow{11}{*}{ Monoterpernos } & Alfa - pineno & $0,8-3,6$ \\
\hline & & Beta - pineno & $0,1-1,6$ \\
\hline & & Terpinoleno & 3 \\
\hline & & Alfa - tuieno & $0,1-2,1$ \\
\hline & & Limoneno & $0,4-2,77$ \\
\hline & & Para - cimeno & $0,4-12,4$ \\
\hline & & Alfa - felandreno, sabineno & Traços $-3,2$ \\
\hline & & Alfa - terpineno & $4,6-12,8$ \\
\hline & & Gama - terpineno & $9,5-28,3$ \\
\hline & & Mirceno & $0,1-1,8$ \\
\hline & & Alfa e beta - felandrano & Traços - 1,9 \\
\hline & \multirow{9}{*}{ Sesquiterpenos } & Beta - cariofileno & 1 \\
\hline & & Aromadendreno & $0,1-6,6$ \\
\hline & & Delta - cadineno & $0,1-7,5$ \\
\hline & & Allo - aromadendreno & 0,3 \\
\hline & & Alfa - muuroleno & 0,1 \\
\hline & & Viridifloreno & $0,3-6,1$ \\
\hline & & Biciclogermacreno & 0,1 \\
\hline & & Alfa - gurjuneno & 0,2 \\
\hline & & Calameno & 0,1 \\
\hline \multirow{8}{*}{ Alcoóis } & \multirow{5}{*}{ Monoterpenóides } & Terpinenol-4 & $29,4-44,9$ \\
\hline & & Alfa - terpineol & $3,5-5$ \\
\hline & & Beta - terpineol & Traços \\
\hline & & p-cimenol-8 & 1 \\
\hline & & Cis -tuianol-e e trans-tuianol-4 & Traços \\
\hline & \multirow{3}{*}{ Sesquiterpenóides } & Globulol & $0,1-3$ \\
\hline & & Viridiflorol & $0,1-1,4$ \\
\hline & & Cubenol & 0,1 \\
\hline \multirow{3}{*}{\multicolumn{2}{|c|}{ Óxidos }} & 1,8-cineol & $0,5-18$ \\
\hline & & Epóxicariofileno & Traços \\
\hline & & 1,4-cineol & Traços \\
\hline
\end{tabular}

Quadro 1: Composição do óleo essencial de Melaleuca alternifolia. Fonte: SILVA, 2004. 


\section{Brazilian Journal of Natural Sciences | Versão On-line ISSN 2595 - 0584 \\ Edição no 1- vol. 3 - outubro 2018 | www.bjns.com.br}

O padrão exigido para a comercialização internacional do óleo essencial de melaleuca é definido por duas instituições: Standards Association of Australian (AS 2782-85) e a International Standard Organization (ISO - 4730, 1996). Ambas as normativas estabelecem a qualidade comercial pelas concentrações dos seus compostos majoritários, o terpinen-4-ol e 1,8-cineol, o primeiro responsável pela atividade antimicrobiana sendo que sua concentração no óleo essencial deve ser no mínimo $30 \%$ e o segundo componente, 1,8 cineol, que possui propriedades irritantes à pele, deve ter uma concentração máxima de 15\% (CASTELO, 2013).

O óleo essencial das folhas da Melaleuca alternifolia, tem uma longa história como antisséptico de uso tópico. Recentemente ganhou uma reputação como antisséptico seguro, eficaz e natural. Isso gerou um ressurgimento de sua popularidade e atualmente é incorporado como antimicrobiano principal ou como conservante natural em produtos farmacêuticos e cosméticos de uso externo (COX, et al., 2000). Além disso, o óleo reduz a taxa de reprodução de patógenos (bactérias, fungos, vírus), e intensifica a resistência contra esses agentes agressores, por esse motivo é útil nas afecções do couro cabeludo, como a caspa, e de pele, como a acne grau I e grau II (TESKE; TRENTINI, 2001). Com outras ações, o óleo essencial de melaleuca também reduziria a inflamação local talvez por diminuir a liberação de histaminas $(\mathrm{KOH}$ et al, 2002). As propriedades anti-inflamatórias contribuem com a cura de feridas crônicas e são baseadas na supressão da produção de mediadores inflamatórios pela ativação dos monócitos (FINLAY-JONES et al., 2001; HART et al., 2000).

É amplamente indicado em casos de acne, onicomicoses, candidíase, herpes labial entre outros (HAMMER et al, 2003) e tem incrível capacidade bactericida tanto nas espécies gram-positivas quanto nas gram-negativas, além de sua atividade antifúngica potente (SILVA, 2001). O uso de um gel para acne com óleo essencial de melaleuca a $5 \%$ demonstrou menos efeitos colaterais quando comparada ao uso de loção com peróxido de benzoíla a 5\%, embora o início da ação de produto seja mais lento (BASSETT et al, 1990). O efeito do pe- róxido de benzoíla não é tão intenso e duradouro como o da melaleuca e causa maior intolerância ao produto (ALONSO, 1998). A concentração ideal para uso da melaleuca em cosméticos é de 2 a $5 \%$ para que este seja usado com segurança (CARVALHO e ALMANCA, 2003).

\section{Ação antibacteriana}

A quantificação da atividade antimicrobiana dos óleos essenciais é indispensável na exploração de sua aplicação. Eles, tal como outros agentes antimicrobianos podem exercer os mais variados efeitos sobre a célula microbiana, quer na sua estrutura, quer no seu funcionamento. (BURT 2004, LAHLOU 2004).

Em muitos casos, a propriedade antimicrobiana se dá pela ação de constituintes monoterpenos que causam danos à membrana celular do microrganismo (COX et al, 2000). O mecanismo de ação bactericida consiste no comprometimento da integridade da membrana celular, consequente perda de material intracelular, incapacidade de manter a homeostase e inibição da respiração (CARSON et al., 2006).

Segundo COX et al (2000), a ação antimicrobiano do óleo essencial de melaleuca pode resultar da habilidade de destruir a barreira permeável das estruturas da membrana celular de bactérias, este é um modo de ação similar aos conservantes como derivados de fenol, clorexidina e derivados do ácido parabenzóico e de desinfetantes ativos contra a membrana celular. Contudo, por possuir cerca de 100 componentes, existe a possibilidade de não ter sido pesquisado todo o potencial de atuação. Sendo assim é possível que outros elementos, ainda não avaliados, contribuam para a atividade antimicrobiana com mecanismo de ação diferente daquele já encontrado (HAMMER et al., 2003).

Dentre os componentes do óleo o componente Terpinen-4-ol está presente em $30-40 \%$ da composição (CARSON et al., 2006), sendo o que detêm a principal atividade antimicrobiana. O 1,8-cienole, considerado irritante da pele, pode aumentar a permeabilidade da membrana facilitando a entrada de outros agentes antimicrobianos e por 
isso alguns autores o consideram como detentor de efeito antimicrobiano marginal. (OLIVEIRA, et al., 2011).

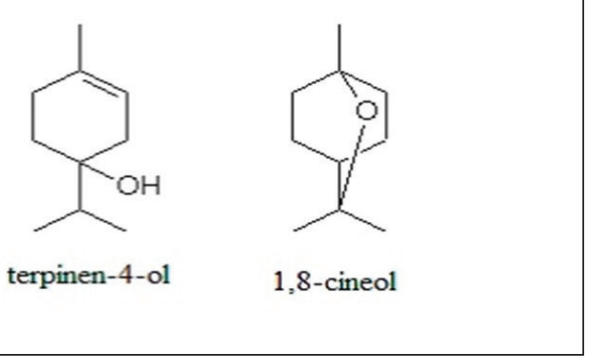

Figura 2: Principais componentes com ação antimicrobiana.

Fonte: OLIVEIRA, et al., 2011.

Dados recentes mostram que o óleo de melaleuca possui amplo espectro de ação antimicrobiano, possuindo efeito bactericida in natura e bacteriostático em baixas concentrações (Wilkinson \& Cavanagh, 2005; Kwiecinski et al., 2008; Vuuren et al., 2009).

\section{Material e Método}

Óleo essencial: O Ativo utilizado foi o óleo essencial puro de Melaleuca alternifolia, lote: 0043/13, fabricado em: 01/13 e vencimento em: $01 / 16$, produzido pela empresa WNF (World's Natural Fragance).

\section{Método}

O presente Trabalho de Conclusão de Curso foi desenvolvido no laboratório de Biologia Molecular e Cultura de Células da Escola de Ciências da Saúde da Universidade Anhembi. A linhagem de fibroblastos L929 foi submetida ao tratamento com diferentes concentrações do óleo essencial de Melaleuca alternifolia. Após os tratamentos foi realizada uma avaliação da viabilidade celular do composto testado frente à linhagem L929.

\section{Cultura celular}

As células da linhagem L-929 foram cultiva- das em meio RPMI com $10 \%$ de soro fetal bovino, $2 \mathrm{mM}$ de L-glutamina, $100 \mathrm{IU} / \mathrm{mL}$ penicilina e $100 \mu \mathrm{g} / \mathrm{mL}$ de estreptomicina. As células foram mantidas em frascos de $25 \mathrm{~cm}^{2}\left(1 \times 10^{5}\right.$ cells $\left./ \mathrm{mL}\right)$ em estufa úmida com atmosfera de $5 \%$ de $\mathrm{CO}_{2}$ a $37^{\circ} \mathrm{C}$. Em todos os experimentos as culturas de fibroblastos foram submetidas ao teste de viabilidade celular utilizando o corante azul de tripano e realizado a leitura em câmara hemocitométrica por microscopia óptica. Todos os experimentos descritos foram realizados quando a viabilidade celular for igual ou superior a $95 \%$.

\section{Avaliação da citotoxicidade (determinação do $\mathrm{IC}_{50}$ )}

Avaliação da citotoxicidade do óleo essencial de Melaleuca Alternifolia foi realizada pelo método de incorporação do corante azul de tripano, onde após 48 horas de incubação o conteúdo de cada poço das culturas de fibroblastos foi recolhido em tubos de $15 \mathrm{~mL}$, e centrifugados a $1500 \mathrm{rpm}$ por 8 minutos. Os pellets foram ressuspendidos em $1 \mathrm{~mL}$ de meio RPMI. Após isso, as soluções de células foram diluídas (1:2) em corante de azul de tripano e a contagem das células viáveis e inviáveis foi realizada em câmara hemocitométrica por microscopia óptica. A soma da contagem de células totais (viáveis e inviáveis de cada poço) foi considerada como $100 \%$ de células, sendo realizados os cálculos para verificar as porcentagens correspondentes às células viáveis e as inviáveis analisadas no experimento.

\section{Ensaios de redução MTT à formazan.}

O teste de redução MTT ([3-(4,5-Dimetiltiazol-2-il)2,5-Difenil Brometo de Tetrazólio]) é usado com grande sucesso para estimar o número de células viáveis em um screening inicial de fármacos. Sua interpretação serve de indicativo da atividade metabólica celular, e o local de ocorrência das reações redox inclui tanto mitocôndrias como o citosol. A redução do sal de MTT à formazan é realizada principalmente pela enzima succinatodesidrogenase, e resulta em cristais de formazan 


\section{Brazilian Journal of Natural Sciences | Versão On-line ISSN 2595 - 0584 \\ Edição no 1- vol. 3 - outubro 2018 | www.bjns.com.br}

insolúveis na cor violeta. A intensidade da coloração é utilizada para medir a atividade mitocondrial e consequentemente a viabilidade celular (MOSMANN et al., 1983). Assim, às células foram tratadas com diferentes concentrações do óleo essencial de Melaleuca alternifolia e na concentração $5 \times 10^{4}$ células por poço, foram adicionados $10 \mu \mathrm{l}$ da solução de MTT $5 \mathrm{mg} / \mathrm{ml}$ (Sigma-Aldrich) em cada poço. Após 4 horas, a placa foi centrifugada, o sobrenadante de cada poço descartado e o pellet com os cristais formado no fundo da placa, dissolvido com $100 \mu \mathrm{L}$ de etanol puro e em seguida homogeneizado em agitador de placas por 15 minutos. A densidade óptica foi medida pelo leitor de microplacas (FlexStation ${ }^{\oplus} 3$ multimode benchtop reader) em $540 \mathrm{~nm}$. A percentagem de sobrevivência celular na presença dos compostos em estudo foi calculada da seguinte maneira:

$$
\text { \% Células viáveis }=\frac{\text { Absorbância por poço }(\text { com droga }) \times 100}{\text { Absorbância do controle }(\text { sem droga })}
$$

Teste de determinação de apoptose através da avaliação da integridade das moléculas de DNA

Para a análise qualitativa de fragmentos de DNA resultante de clivagem internucleossomal, $5 \times 10^{5}$ de células/mL da linhagem L929, tratada com diferentes concentrações de Melaleuca alternifolia, foram submetidas à extração de ácidos nucleicos segundo Sambrook \& Russel, 2001. Após a extração do DNA genômico, as amostras e os padrões de bandas de DNA foram analisados por eletroforese em gel de agarose em concentração de $0,8 \%$ e $1,5 \%$, corados com brometo de etídio. Os géis foram visualizados e fotografados sobre luz ultravioleta usando um fotodocumentador com sistema de captura digital de imagem.

\section{Avaliação da ação antimicrobiana}

Meio de Cultura Mueller - Hinton

\section{Cepa teste}

Foi utilizada uma cepa teste de Propionibacterium acnes ATCC 11827, gentilmente cedida pela empresa PROBAC do Brasil, conservada em meio Tioglicolato e repicada em meio BHI para enriquecimento. A suspensão da cepa foi realizada em solução salina $(\mathrm{NaCl}$ a $0,85 \% \mathrm{p} / \mathrm{v})$, a qual foi padronizada de acordo com o tubo 0,5 da escala McFarland correspondendo à concentração de aproximadamente $108 \mathrm{UFC} / \mathrm{mL}$ (técnica adaptada de BAUER et al., 1966).

\section{Avaliação da Atividade}

Foi utilizado um disco contendo o antibiótico Clindamicina (controle), que é considerado o mais potente para acne devido à supressão da proliferação da bactéria Propionibacterium acnes nos folículos pilosos afetados, com redução da inflamação local. Seu uso é tópico e a concentração utilizada está entre 1 a 2\% (COSTA e BAGATIN, 2013). Utilizaram-se discos embebidos com $25 \mu \mathrm{L}, 50 \mu \mathrm{L}$ e $75 \mu \mathrm{L}$ do óleo essencial de Melaleuca alternifolia brutos e em seguida, colocados em placas de Petri estéreis contendo ágar Muller-Hinton inoculado com a suspensão bacteriana descrita anteriormente, com o auxílio de "swabs" estéreis, o teste foi feito em triplicata. Após isso houve incubação das placas a $37^{\circ} \mathrm{C}$ por 24 horas e foram observados os halos de inibição sobre a cepa bacteriana ensaiada. Os resultados foram expressos em milímetros dos diâmetros dos halos formados ao redor dos discos (Adaptado de OLIVEIRA et. al., 2006).

\section{Pour-plate}

O objetivo da técnica de semeadura em profundidade é obter colônias isoladas. Nesta técnica 1,0 $\mathrm{mL}$ de suspensão de microrganismo e diferentes concentrações do ativo $(25 \mu \mathrm{l}, 50 \mu \mathrm{l}$ e $75 \mu \mathrm{l})$ foram adicionados em placas estéreis e em seguida 15 a $20 \mathrm{~mL}$ de ágar TSA fundido foi adicionado por cima. Essa técnica foi feita em triplicata. As placas foram suavemente submetidas a movimentos ro- 
tatórios, visando uma perfeita mistura da cultura com o ágar. Nesta técnica tomou-se cuidado para não adicionar o meio em temperatura elevada sobre o inóculo, pois isto poderá matar os microrganismos.

\section{Detalhamento da Técnica}

Isolamento de micro-organismos: homogeneização e diluição seriada; junto à chama do bico de Bunsen, transferiu-se 1, $0 \mathrm{~g}$ da amostra complexa coletada para um frasco contendo $9,0 \mathrm{ml}$ de solução salina esterilizada; agitou-se vigorosamente a suspensão preparada no passo anterior e deixou por 10 minutos sob agitação de $150 \mathrm{rpm}$, de modo a obter uma suspensão homogênea da amostra, facilitando a suspensão da maior parte das células dos micro-organismos adsorvidas nas partículas da amostra;

junto à chama do bico de Bunsen, transferiuse 1,0 mL da suspensão original (preparada acima - diluição $10^{-1}$ ) para tubos de ensaio contendo $9,0 \mathrm{ml}$ de solução salina estéril, de modo a obter a diluição $10^{-2}$; foi feito diluições sucessivas até $10^{-4}$ (1:10000). Foi homogeneizada a amostra em suspenção (utilizando vortex) em cada nova diluição realizada; foram realizadas placas controle em triplicata, contendo $1,0 \mathrm{ml}$ de cada diluição e o meio TSA. Nas placas teste, foram plaqueados $1,0 \mathrm{~mL}$ de cada diluição, adicionado às concentrações de ativo em triplicata e adicionou-se o meio TSA;As placas foram incubadas a $35^{\circ} \mathrm{C}$ de 2 a 3 dias. Foi realizada a contagem.

\section{Análise estatística}

Os dados foram analisados através do teste estatístico "Análise de Variância (ANOVA)" e posteriormente o teste de comparação múltipla de Tukey, com significância de $\mathrm{p}<0.05$, para a comparação entre os grupos. Foi utilizado o Software GraphPad-Prism V3.02.

\section{Resultados}

Os resultados obtidos nos ensaios realizados laboratório de Biologia Molecular e Cultura de Células da Escola de Ciências da Saúde da Universidade Anhembi, estão descritos abaixo.

\section{Teste da avaliação de citotoxicidade}

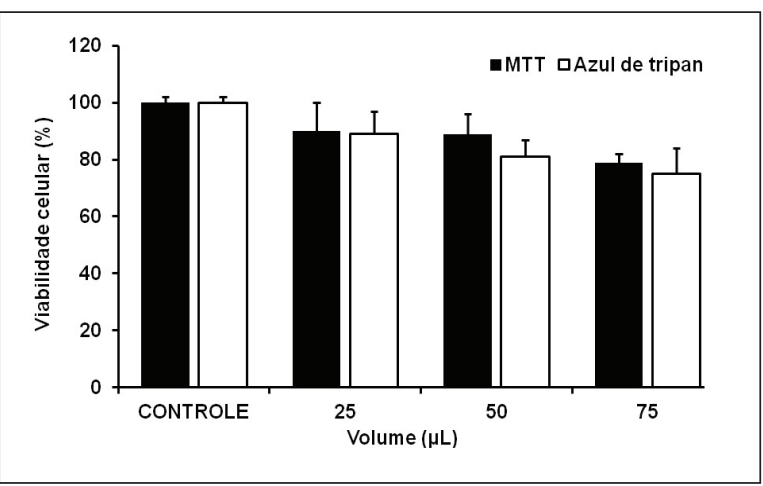

Figura 3: Viabilidade de fibroblastos L-929 obtida após tratamento com óleo essencial de melaleuca depois de $72 \mathrm{~h}$ de exposição. Testes realizados: teste de redução do MTT e viabilidade por azul de tripan. Todos os experimentos foram realizados em triplicata e estão representados pela média e desvio padrão. Os dados foram analisados através do teste estatístico "Análise de Variância (ANOVA)" e posteriormente o teste de comparação múltipla de Tukey.

\section{Teste de determinação de apoptose}

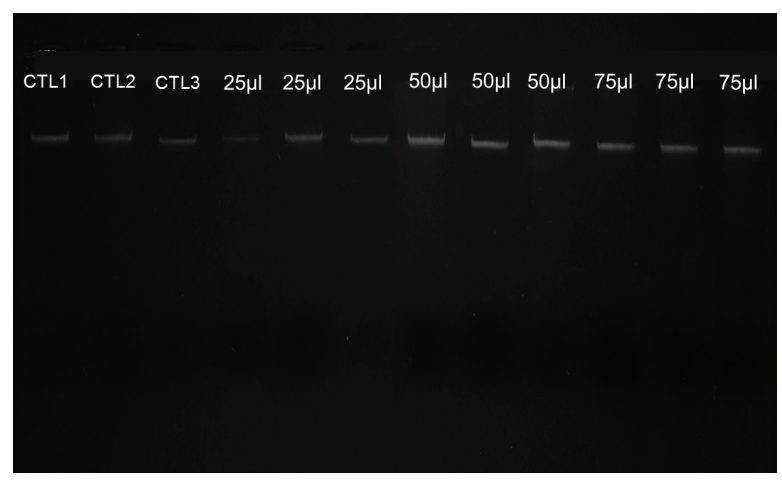

Figura 4: Corrida de eletroforese em gel de agarose para determinação da integridade das moléculas de DNA. 
Brazilian Journal of Natural Sciences | Versão On-line ISSN 2595 - 0584

Edição no 1- vol. 3 - outubro 2018 | www.bjns.com.br

Teste antimicrobiano pela técnica de Mueller-Hinton

\begin{tabular}{|l|l|l|l|l|}
\hline P.acnes & Controle & $\mathbf{2 5 \mu \mathrm { L }}$ & $\mathbf{5 0} \boldsymbol{\mu L}$ & $\mathbf{7 5} \boldsymbol{\mu L}$ \\
\hline 1 & $15 \mathrm{~mm}$ & $14 \mathrm{~mm}$ & $17 \mathrm{~mm}$ & $19 \mathrm{~mm}$ \\
\hline 2 & $17 \mathrm{~mm}$ & $11 \mathrm{~mm}$ & $15 \mathrm{~mm}$ & $22 \mathrm{~mm}$ \\
\hline 3 & $13 \mathrm{~mm}$ & $12 \mathrm{~mm}$ & $11 \mathrm{~mm}$ & $18 \mathrm{~mm}$ \\
\hline Média \pm & $15,0 \mathrm{~mm} \pm 2,0$ & $12,3 \mathrm{~mm} \pm 1,5$ & $14,3 \mathrm{~mm} \pm 3,0$ & $19,6 \mathrm{~mm} \pm 2,1$ \\
\hline
\end{tabular}

Tabela 1: Susceptibilidade de cepa de P. acnes frente à ação do óleo essencial de melalueca (resultados expressos em diâmetro dos halos de inibição do crescimento microbiano em $\mathrm{mm}$ ).

Figura 5: Foto ilustrativa mostrando o resultado do teste de sensibilidade utilizando o meio de cultura Mueller - Hinton.

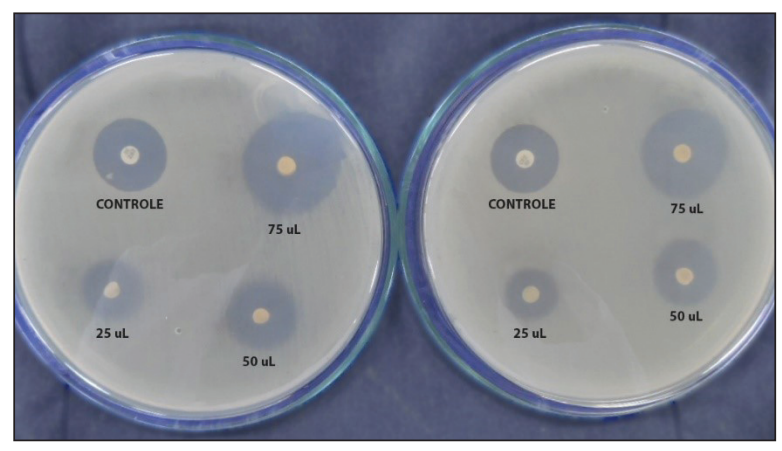

Teste antimicrobiano pela técnica de pour-plate

\begin{tabular}{|c|c|c|c|c|}
\hline Cepa & UFC - Controle & $\mathbf{2 5 u L}$ & $\mathbf{5 0 u L}$ & $\mathbf{7 5 u L}$ \\
\hline \multirow{2}{*}{ Propionibacterium } & 93 & 94 & 86 & 78 \\
acnes & 102 & 90 & 89 & 75 \\
& 99 & 89 & 84 & 81 \\
\hline \multirow{2}{*}{ Média e DP $( \pm)$} & $98 \pm 4,5$ & $91,0 \pm 2,6$ & ${ }^{\star} 86,3 \pm 2,5$ & ${ }^{* *} 78 \pm 3,0$ \\
\hline
\end{tabular}

Tabela 2: Susceptibilidade de cepa de P. acnes frente à ação do óleo essencial de melalueca (resultados expressos pela média e desvio padrão de unidades formadoras de colônia - UFC).

Figura 6: Susceptibilidade de cepa de P. acnes frente à ação do óleo essencial de melaleuca (resultados expressos pela média e desvio padrão de unidades formadoras de colônia - UFC). Os dados foram analisados através do teste estatístico "Análise de Variância (ANOVA)" e posteriormente o teste de comparação múltipla de Tukey.

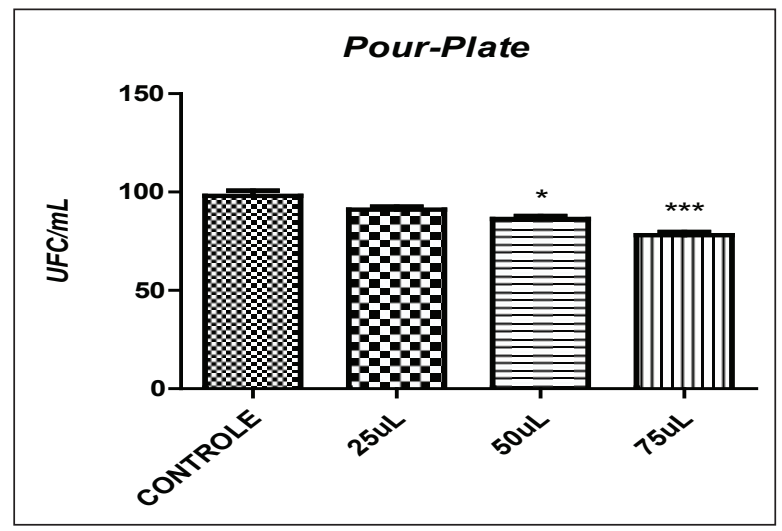




\section{Discussão}

De acordo com os resultados obtidos podemos sugerir que o óleo essencial de melaleuca apresenta potencial antimicrobiano e praticamente não se mostrou citotóxico. Neste sentido, o teste de sensibilidade ao óleo essencial de melaleuca realizado através do meio Mueller Hinton, mostrou que o óleo essencial de melaleuca foi efetivo contra a cepa Propionibacterium acnes, mesmo não apresentando diferenças significativas em relação ao controle (clindamicina), que como dito anteriormente é um potente antibiótico com ação na Propionibacterium acnes (Tabela1). Esses resultados corroboram os estudos realizados por Raman, Weir e Bloomfield em 1995, que mostraram atividade antimicrobiana contra Propionibacterium acnes, Staphylococcus aureus, Staphylococcus epidermidis; e Simões et.al., em 2002, que mostraram resultados que indicam ampla ação contra uma gama de bactérias Gram positivo/negativas e contra diferentes fungos, entre eles, C. albicans, Trichophyton rubrum, T. mentagrophytes, T. tonsurans, Aspergillus niger, Penicillium sp, Epidermophyton floccosum e Microsporum gypsum. Por fim, podemos citar o trabalho de Carson et al. em 1995, onde foi testada a atividade in vitro do óleo essencial de melaleuca contra 66 cepas de S. aureus, sendo 64 delas resistentes a meticilina e observaram que todas as cepas foram sensíveis e apresentaram Concentração Inibitória Mínima de 0,312\% e Concentração Bactericida Mínima de 0,625\%.

Com o objetivo de verificarmos, através de outra técnica, o potencial antimicrobiano do óleo essencial de melaleuca, também foi realizado a metodologia Pour-Plate, e os resultados apresentados, ao contrário do teste de sensibilidade, mostraram redução significativa no número de UFC após realizarmos o tratamento com o óleo essencial de melaleuca. Vale ressaltar que o primordial no óleo essencial de Melaleuca é o teor de 1,8 cineol mais baixo possível e o de terpineol-4 mais alto possível. Pela ISO com 3\% de cineol e 36\% de terpineol-4 já está ótimo, sendo que o óleo estudado se enquadrado na qualidade KBA que é a máxima qualidade de Tea Tree.
Em relação à citotoxicidade, os testes realizados indicaram que as concentrações do óleo essencial de melaleuca utilizadas no trabalho não foram citotóxicas, uma vez que nem a técnica de azul de tripan e nem o MTT mostraram redução significativa na viabilidade de células L-929 (figura 3). Além disso, podemos observar na figura 4 , que a extração de DNA mostrou integridade, indicando que não houve ativação de morte celular pela ausência de fragmentação do material genético. Neste sentido, alguns trabalhos mostram que a melaleuca apresenta toxicidade dose dependente, como demonstrou Söderberg e colaboradores em 1996 e Loughlin et al, em 2008. Deste modo, não podemos desconsiderar variáveis que podem justificar nossos resultados de citotoxicidade, como por exemplo, o tempo de exposição, que em alguns autores citados acima foi de $24 \mathrm{~h}$, mas com doses bem maiores do que as testadas neste trabalho. Além disso, a própria toxicidade dose-dependente deve ser levada em conta.

\section{Conclusão}

Com base nos resultados obtidos, podemos concluir que o óleo essencial de Melaleuca alternifolia apresentou uma ação antimicrobiana satisfatória sobre o Propionibacterium acnes, ao mesmo tempo em que não se mostrou citotóxico nas células L-929, nas concentrações testadas.

\section{Referências Bibliográficas}

BASSETT, I. B.; PANNOWITZ, D. L.; BARNETSON, R. S. A Comparative Study Of TeaTree Oil Versus Benzoylperoxide In The Treatment Of Acne. Med. Aust., vol. 153, 1990. Pág 455.

BAUER, A. W.; KIRBY, W. M. M.; SHERRIS, J. C.; TURCK, M. Antibiotic Susceptibility Testing by a Standardized Single Disk Method. American Journal of Clinical Pathology, Washington, v. 45, 1966. Pág 493-496.

BURT, S. Essential Oils: Their Antibacterial Properties and Potential Applications in Foods - A Review. International Journal of Food Microbiology, 2004. Pág. 223, 253. 
CARVALHO, J. C. J.; ALMANCA, C. C. J. Formulário de Prescrição Fitoterápica. São Paulo: Atheneu, 2003. Pág 115, 117.

CARVALHO, G. H; LEAL, P. F; MEIRELES, M. A. A. Destilação por Arraste a Vapor de Alecrim, Camomila, Erva-Baleeira e Erva Doce: Estudo da Cinética de Extração. XVI Congresso Interno de Iniciação Cientifica da Unicamp, 2008.

CARSON, C.F.; HAMMER, K.A.; RILEY, T.V. Melaleuca Alternifolia (Tea Tree) Oil: A Review of Antimicrobial and Other Medicinal Properties. Clinical Microbiology Reviews, v.19, 2006. Pág 50, 62.

CASTELO, A.V.M.; AFONSO, S.R.; MELO, R.R.; DEL MENEZZI, C.H.S.; CAMILO, J.; VIEIRA, R.F. Rendimento e Composição Química do Óleo Essencial de Melaleuca alternifolia Cheel, na Região do Distrito Federal. Revista Brasileira de Ciências Agrárias. 2013.

CORAZZA, S. Aromacologia - Uma Ciência de Muitos Cheiros. São Paulo: Editora SENAC, 2002. Pág 243, 412.

COSTA, C. S.; BAGATIN, E. Evidências sobre o Tratamento da Acne. Centro Cochrane do Brasil e Departamento de Dermatologia da Escola Paulista de Medicina - Universidade Federal de São Paulo (EPM-Unifesp), 2013. Pág. 10.

COX, S. D.; MANN, C. M.; MARKHAM, J. L. O Modo de Ação Antimicrobiana do Óleo Essencial de Melaleuca Alternifolia (Tea Tree). Journal of Applied Microbiology. 2000. Pág 170, 175.

FINLAY-JONES, J.; HART, P.; RILEY, T. Anti-inflammatory Activity of Tea Tree Oil. Nedlands, Australia: Rural Industries Research and Development Corporation, 2001.

HART, P.H.; BRAND, C.; CARSON, C.F. et al. Terpinen-4-Ol, The Main Component of The Essential Oil of Melaleuca alternifolia (Tea Tree Oil) Suppresses Inflammatory Mediator Production by Activated Human Monocytes. Inflammation Research, v. 49, 2000. Pág 619.

HAMMER, K. A.; CARSON, C. F.; RILEY, T. V. Antifungal Activity of the Components of Melaleuca alternifolia (Tea Tree) Oil. Appl. Microbiology. 2003. Pág 853.

KWIECINSKI, J.; EICK, S.; WÓJCIK, K. Ef- fects of Tea Tree (Melaleuca alternifolia) Oil on Staphylococcus aureus in Biofilms and Stationary Growth Phase. International Journal of Antimicrobial Agents, vol.33, 2008. Pág. 342 - 347.

KOH, K. J. et al. Tea Tree Oil Reduces Histamine-Induced Skin Inflammation. British Journal of Dermatology, Austrália, vol. 147, 2002. Pág 121.

LOUGHLIN, R.; GILMORE, B. F; MCCARRON, P. A.; TUNNEY, M. M. Comparison of The Cidal Activity of Tea Tree Oil and Terpinen-4-Ol Against Clinical Bacterial Skin Isolates and Human Fibroblast Cells. Journal compilation - The Society for Applied Microbiology, 2008. Pág 428.

MAIDEN \& BETCHE. Melaleuca alternifolia Cheel. Plants For a Future, 2013.

MARTINS, A. P.; NOGUEIRA, M. T.; COSTA, M. C.; SALGUEIRO L. Requisitos de qualidade em óleos essenciais: a importância das monografias da Farmacopeia Europeia e das normas ISSO. Revista de Fitoterapia, 2011. Pag. 36 e 39.

OLIVEIRA, R. A. G.; LIMA, E. O.; VIEIRA, W. L.; FREIRE, K. R. L.; TRAJANO, V. N.; LIMA, I. O.; SOUZA, E. L.; TOLEDO, M. S.; SILVA-FILHO, R.N. Estudo da Interferência de Óleos Essenciais Sobre a Atividade de Alguns Antibióticos Usados na Clínica. Rev. Bras. Farmacogn., João Pessoa, v. 16, 2006. Pág 77, 79.

OLIVEIRA, A.C.M.; FONTANA, A.; NEGRINI, T.C.; NOGUEIRA, M.N.M.; BEDRAN, T.B.L.; ANDRADE, C.R.; SPOLIDORIO, L.C.; SPOLIDORIO, D.M.P. Emprego do Óleo de Melaleuca alternifolia Cheel (Myrtaceae) na Odontologia: Perspectivas Quanto à Utilização como Antimicrobiano Alternativo às Doenças Infecciosas de Origem Bucal. Rev. Bras. Pl. Med., Botucatu, v.13, 2011. Pág 492, 499.

SAMBROOK, J.; RUSSELL, D. W. Molecular Cloning: a Laboratory Manual. New York: Cold Spring Harbor Laboratory, 2001.

SANTOS, A.; PADUAN, R. H.; GAZIN, Z. C.; JACOMASSI E.; D' OLIVEIRA, P. S.; CORTEZ, D. A. G.; CORTEZ, L. E. R. Determinação do Rendimento e Atividade Antimicrobiana do Óleo Essencial de Cymbopogon Citratus (DC.) Stapf em Função de Sazonalidade e Consorciamento. 
Scielo - Revista Brasileira de Farmacognosia, 2009. SILVA, A.R. Aromaterapia em Dermatologia Estética. São Paulo: Roca, 2004. Pág 299, 324-5 SILVA, A. R. Tudo Sobre Aromaterapia: Como Usa-Lá Para Melhorar sua Saúde Física, Emocionl e Financeira. 2. ed. São Paulo: Ed. Raroca, 2001. Pág 302.

SIMÕES, R. P. et al. Efeito do Óleo Essencial de Melaleuca Alternifolia Sobre a Infecção Estafilocócica. Rev. Lecta, Bragança Paulista. 2002. Pág 143, 152.

SODERBERG, T. A.; JOHANSSONB, A.; GREFC, R. Toxic Effects of Some Conifer Resin Acids and Tea Tree Oil on Human Epithelial and Fibroblast Cells. Elsevier Science Ireland Ltd., 1996. Pág 99.

TESKE, M.; TRENTINI, A. M. M. Herbário Compêndio de Fitoterapia. 4. ed. Curitiba: Herbarium Lab. Bot. Ltda., 2001.

VADEMÉCUM.; Prescripción. 4. ed. Barcelona: Masson, 2003. Pág 354.

VUUREN, S.F.; SULIMAN, S.; VILJOEN, A.M. The Antimicrobial Activity of Four Commercial Essential Oils in Combination with Conventional Antimicrobials. Letters in Applied Microbiology, vol. 48, 2009. Pág. 440 - 446.

WALTERS, C. Aromaterapia: Para uma Vida Saudável. São Paulo: Könermann, 2000. Pág 90 e 91.

WILKINSON, J.M.; CAVANAGH, H.M.A. Antibacterial Activity of Essential Oils from Australian Native Plants. Phytotherapy Research, v.19, 2005. Pág. 643 - 646.

WHO. Monographs on selected medicinal plants. Department of Essential Drugs and Medicines Policy, World Health Organization. 1999. 